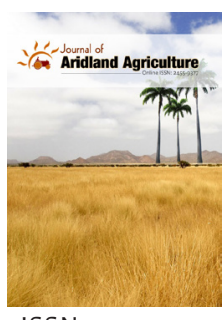

ISSN: $2455^{-9} 9377$

\title{
Actual evapotranspiration evaluation based on multi-sensed data
}

\author{
Mohammed Ahmed El-Shirbeny 1,2,3 *, Samir Mahmoud Saleh4 \\ 'National Authority for Remote Sensing and Space Sciences (NARSS), Egypt, ${ }^{2}$ Arab Organization for Agricultural \\ Development (AOAD), ${ }^{3}$ International Center for Agriculture Research in the Dry Areas (ICARDA), ${ }^{4}$ Laboratory for \\ Agricultural Climate, Agricultural Research Center, Dokki, Giza, Egypt
}

\begin{abstract}
On overcast days, the significance of active and passive remote sensing data integration becomes clear. On cloudy days, the absence of passive remote sensing data limits the benefit of large-scale satellite data in cloudy regions, while active remote sensing has the advantage of being able to pierce the cloud and gather data underneath the cloud. The primary goal of this study is to assess the advantages of integrating active and passive remote sensing data to identify real evapotranspiration (ETa). Sentinel-1 radar data is active data, while Landsat-8 data is passive data. During the 2016 summer season, multi-date Landsat-8 and Sentinel-l data were utilized. Clay is the predominant soil texture in the research area. The meteorological data were used to calculate ETo using the FAO-Penman-Monteith (FPM) method, and the Lysimeter data were used to test the calculated ETa. The Normalized Difference Vegetation Index (NDVI) and Crop Water Stress Index (CWSI) are calculated using Landsat-8 data (CWSI). Crop Coefficient $(\mathrm{Kc})$ is computed using NDVI. ETa was calculated using the CWSI, Kc, and ETo. Data from the Sentinel-l satellite's backscattering $(d B)$ C-band Synthetic Aperture Radar (SAR) was correlated with Kc and used to determine ETa. The Root Mean Square Error (RMSE) calculated relevant findings for active and passive satellite data individually, as well as the combining procedure. The RMSE for Sentinel-1, Landsat-8, and combination techniques was 0.89, 0.24, and 0.31 ( $\mathrm{mm} /$ day $)$, respectively.
\end{abstract}

KEY WORDS: Sentinel-1, Landsat-8, Backscattering (dB), Lysimeter, Water Stress, and Egypt

Received: April 26, 2021
Revised: August 08, 2021

Accepted: August 09, 2021

Published: August 31, 2021

*Correspending Author: Mohammed Ahmed

El-Shirbeny

E-mail: mshirbeny@yahoo. com-m.el-shirbeny@cgiar. org at regional and global sizes during the past several decades. Remotely sensed data and methods have been utilized and assessed for determining ET (Rwasoka et al., 2011; El-Shirbeny et al., 2014a; Tadesse et al., 2015; El-Shirbeny et al., 2015, ElShirbeny et al., 2015, El-Shirbeny et al., 2015, El-Shirbeny et al., 2015, Oki \& Kanae, 2006; Mohamed et al., 2020; El-Shirbeny et al., 2020). Water stress, stomata conductivity, heat flux, transpiration, and cooling all lead plants to close their stomata, resulting in less evaporation and a higher canopy temperature than non-stressed plants (Stokcle, \& Dugas, 1992; Tolba et al., 2020).

ET is a key component in many environmental phenomena, including meteorological, agricultural, and hydrological uses (Baioumy et al., 2016; El-Shirbeny \& Abu-Talib, 2018, ElShirbeny et al., 2019; El-Shirbeny et al., 2021). When using traditional techniques, reliable measurement of in situ ET is often expensive, time-consuming, and restricted in size. Furthermore, frequent observations are required to determine temporal variations caused by adverse weather influences. One of the most important topics in remote sensing operations is satellite-based ET estimate. Using passive remote sensing, several studies have been conducted to determine ET
Satellite and aerial data, as well as remotely sensed ground-based data utilized at the farm level, have been used to estimate ET
Copyright: (-) The authors. This article is open access and licensed under the terms of the Creative Commons Attribution License (http://creativecommons.org/licenses/by/4.0/) which permits unrestricted, use, distribution and reproduction in any medium, or format for any purpose, even commercially provided the work is properly cited. Attribution - You must give appropriate credit, provide a link to the license, and indicate if changes were made. 
(Bastiansen et al., 1998; Allen et al., 2007; Wu et al., 201 1; ElShirbeny et al., 2016).

Based on remotely sensed data, curves (Kc) may be detected and established (Dibella et al., 2000, El-Shirbeny et al., 2015; El-Shirbeny et al., 2016). Several studies have been conducted to describe the Kc Curve fluctuation and its relationship with satellite-derived NDVI, as well as the direct relationship between NDVI and leaf area index (LAI) (i.e., Aboelghar et al., 2010, El-Shirbeny et al., 2014b, El-Shirbeny et al., 2015).

Crop water stress must be monitored and identified in order to discover actual water use throughout the growing season. Direct measurements of plant water content are time-consuming and expensive procedures. Therefore they are inapplicable to long-term and large-scale studies. The thermal infrared (TIR) spectrum was used to create the remote sensing system (Idso et al., 1981; Jackson et al., 1981). The rate of crop sweat is shown by the connection between surface temperature and crop water stress. The transpired water cools the crop canopy. When a crop is subjected to water stress, transpiration decreases, and the crop’s surface temperature rises (Jackson, 1982).

Crop water stress is linked to soil moisture. Because soil moisture has a complex structure, monitoring regional and temporal variations in soil moisture is critical for ecological equilibrium (Mohamed et al., 2020). Active microwave remote sensing technologies have lately been preferred in soil moisture investigations because of the impressive penetrating capabilities of the radar signal to the surface. The availability of soil water on a large scale is critical for irrigation water management and water resource planning.

Data from active and passive remote sensing are very useful for estimating soil water availability (Oki \& Kanae, 2006; ElShirbeny \& Abu-Talib, 2017; Mohamed et al., 2020). The most popular active microwave remote sensing technology for Earth observation is Synthetic Aperture Radar (SAR).

In the 1970s and 1980s, the triangle and (CWSI) methods were utilized and developed. Thermal data was formerly collected using a portable infrared thermometer instrument, but with the launch of the second generation of Landsat satellite series (TM, Landsat 4), scientists began to rely on space-borne data. The SEBAL (Bastiaanssen et al., 1998) and SEBS (Su, 2002) models represent a new era in the development of evapotranspiration models in the 1990s and early 2000s. The primary inputting thermal data for these models come from Landsat, MODIS, and NOAA/AVHRR. METRIC (Allen et al., 2007), ETWatch (Wu et al., 2008), and ETlook (Bastiaanssen et al., 2012) have been created during the past decade to cope with fresh satellite data and address the gaps in the SEBAL and SEBS models. Researchers are continually working to improve and combine these models in order to improve performance and accuracy (El-Shirbeny et al., 2019). The primary goal is to examine the combined ET monitoring data from Sentinel-1 and Landsat-8.

\section{MATERIALS AND METHODS}

\section{Study Area Description}

The location of the study area is represented in Figure 1. The Zagazig station is used to estimate $E T$, and the data of Lysimeter was used to evaluate the estimated ETa. Before planting, soil samples were taken. The mechanical and chemical soil analyses were performed at Ain Shams University's ALARC laboratory. The soil characteristics showed clay texture, where clay and sand contents were high as $56 \%$ and $17 \%$, respectively, while bulk density ranged from 1.3 to $1.6 \mathrm{~g} / \mathrm{cm}^{3}$. According to (Saxton \& Willey 2006), the average of soil water parameters in the research region is as follows: available water is $0.14\left(\mathrm{~cm}^{3} / \mathrm{cm}^{3}\right)$, the wilting point is $0.33\left(\mathrm{~cm}^{3} / \mathrm{cm}^{3}\right)$, field capacity is $0.47\left(\mathrm{~cm}^{3} / \mathrm{cm}^{3}\right)$, and saturation is $0.54\left(\mathrm{~cm}^{3} / \mathrm{cm}^{3}\right)$. The drainage rate was $0.2(\mathrm{~cm} / \mathrm{hr})$.

\section{Data Availability}

Ground meteorological data, Lysimeter data, optical satellite data (Landsat-8), and C-band SAR satellite Sentinel-1 were all utilized.

\section{Weather Data}

Meteorological data, including maximum temperature, minimum temperature, maximum relative humidity, minimum relative humidity, wind speed, and solar radiation, were collected

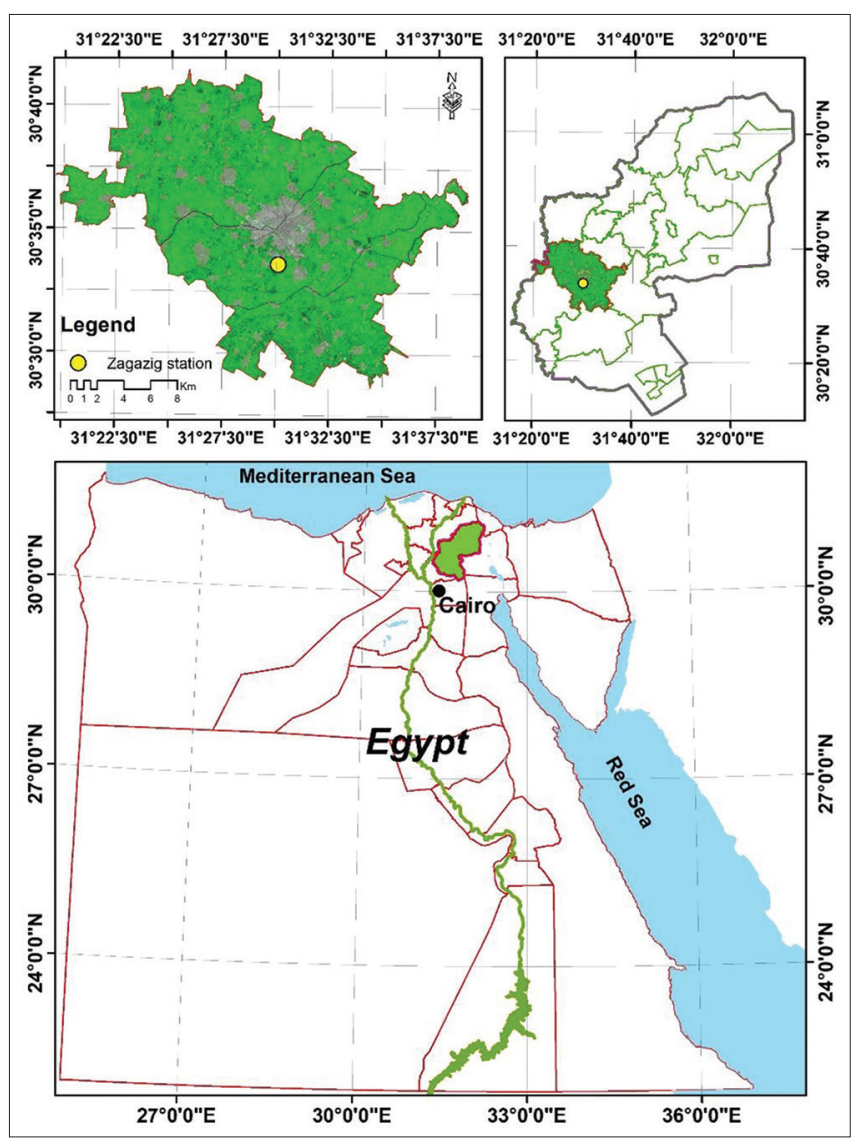

Figure 1: Location map of the study area 
using the Zagazig ground meteorological station. The FPM model was used to estimate ETo from May to September 2016 at the Zagazig meteorological station.

\section{Lysimeter Data}

The Lysimeter was designed to measure ET from a row crop. The data were gathered from three lysimeters, each with a surface area of $1.0 \mathrm{~m}$ by $1.0 \mathrm{~m}$. On $0.5,1.0$, and 1.5 meters, the percolate was collected in different stages. The Corn field was planted on May 25, 2016, and harvested on September 3, 2016. Because precipitation is uncommon during the summer, the typical rain gauge did not gather water in 2016. Irrigation was the sole source of water in the research region. The scheduled irrigation for Lysimeter; irrigation time and quantity is indicated in Table 1. The water balance in the Lysimeter may be expressed as follows: -

$$
\Delta S=I-E T-P
$$

Where; $\Delta S$ is the change in soil moisture, $\mathrm{I}$ is irrigation, ET is evapotranspiration, and $P$ is deep percolation. The main disadvantage of the Lysimeter was that it could only collect fluids under saturated gravity flow. If the applied water exceeds the saturation threshold, the percolation data is only recorded during two or three days after irrigation. The Lysimeter water volume measurements (Figure 2) have been used to estimate ET-Lysimeter due to equation (1). Figure 3 shows the measured ET using Lysimeter ( $\mathrm{mm} /$ day).

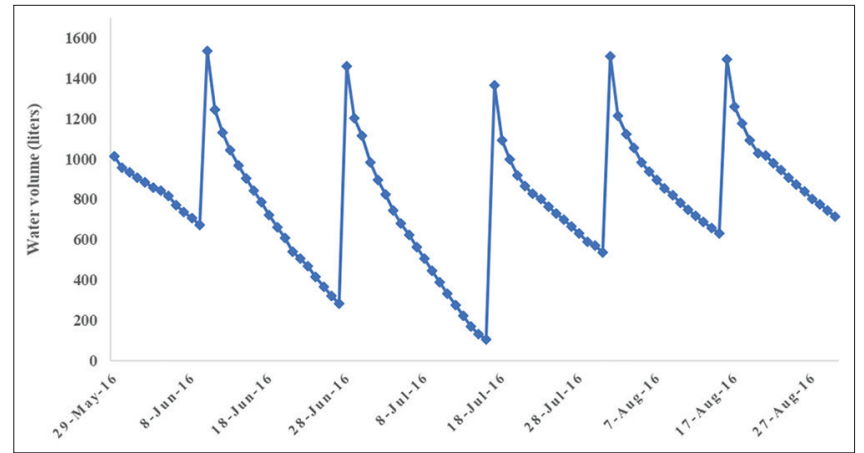

Figure 2: Lysimeter water volume measurements during the summer season, 2016

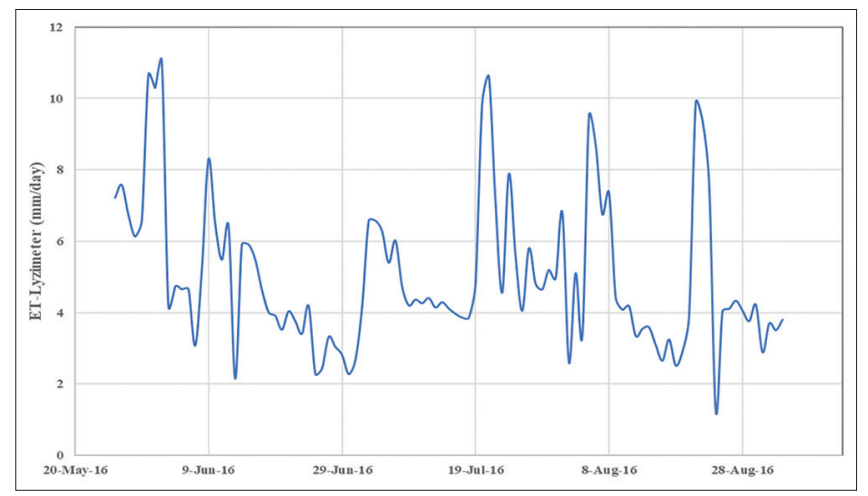

Figure 3: Measured ET using Lysimeter ( $\mathrm{mm} /$ day)

\section{Remote Sensing Data}

Landsat-8 and Sentinel-1 data from several dates were utilized. Table 2 shows the distribution of satellite data time for Landsat- 8 and Sentinel-1 throughout the 2016 summer season. Around 10:15 a.m., the Landsat-8 (paths 176 and 177/row 039) was launched. Sentinel-1 radar data with a 10-meter ground resolution and local time with a 30-meter ground resolution were utilized.

\section{Landsat Data Processing}

Landsat 8 data were obtained from the USGS website and processed for radiometric and atmospheric corrections. The Quick Atmospheric Correction (QUAC) method was used to convert digital number (DN) values into reflectance values and reduce the effects of atmospheric scattering.

\section{Radar Data Processing}

SNAP software is used to calibrate the sentinel-1 data. The goal of SAR calibration, based on SNAP assistance, is to provide pictures in which the pixel values may be directly linked to the radar backscatter of the scene. Four calibrations are provided by the level-1 goods. Look-Up Tables (LUTs) are used to get 0i, 0i, and I or to reach the Digital Number (DN). LUTs use a rangedependent gain that counts the absolute calibration constant. A constant offset is also utilized for GRD goods. The radiometric calibration is practical through the following equation:

$$
\operatorname{value}(i)=\frac{\left|D N_{i}\right|^{2}}{A_{i}^{2}}
$$

where, based on the nominated LUT, value $(\mathrm{i})=$ one of $\beta^{\circ}$, $\sigma^{\circ}{ }_{i}$ or original DN, $\mathrm{A}_{\mathrm{i}}=$ one of bataNought $(i)$, bsigmaNought $(i)$, gamma $(i)$ or $\operatorname{dn}(i)$, Bi-linear interpolation is used for any pixels that fall between points in the LUT. After calibration, the backscattered VV-polarization data are used to indicate the crop and soil water content.

\section{Supervised Classification}

Landsat- 8 data are combined with ground data to identify land-use groups. A maximum likelihood classifier is a common approach for classifying satellite data using a pixel-based methodology in which each pixel has one value and is classified as a single land-use class (Li et al., 2014). The likelihood (Lk) is well-defined as the probability of a pixel fitting to a particular

Table 1: Scheduled irrigation for Lysimeter; irrigation time and quantity

\begin{tabular}{llc}
\hline Date & N0 of Irrigations & Applied water $\left(\mathrm{m}^{3} / \mathrm{ha}\right)$ \\
\hline 25-May-16 & Agriculture & 1320 \\
10-Jun-16 & Irri. 1 & 950 \\
28-Jun-16 & Irri. 2 & 1230 \\
15-Jul-16 & Irri. 3 & 1250 \\
1-Aug-16 & Irri. 4 & 970 \\
16-Aug-16 & Irri. 5 & 900 \\
Total & & 6620 \\
\hline
\end{tabular}


class. To retain the original pixel values, the Landsat- 8 data were re-sampled using the closest neighbor method.

\section{Evapotranspiration (ET)}

The crop evapotranspiration (ETc) is computed in two stages: first, the reference evapotranspiration (ETo) is determined, and then the crop coefficient (kc) is given (Allen et al., 1998). Equation (3) brings the two phases together.

$$
E T c=E T_{O}{ }^{*} \mathrm{Kc}
$$

Meteorological data is required to calculate ETo. The FAO-Penman-Monteith (FPM) technique is appropriate for use in the research area (El-Shirbeny \& Abdellatif, 2017). (Allen et al., 1998) developed Equation (4) to compute $\mathrm{ETo}(\mathrm{mm} / \mathrm{day})$.

$$
\text { ETo }=\frac{0.408 \Delta\left(\mathrm{R}_{\mathrm{n}}-\mathrm{G}\right)+\gamma \frac{900}{\mathrm{~T}+273} \mathrm{u}_{2}\left(\mathrm{e}_{s}-\mathrm{e}_{a}\right)}{\Delta+\gamma\left(\mathrm{l}+0.34 \mathrm{u}_{2}\right)}
$$

where; $R_{n}$, net radiation $\left[M J / m^{2} / d a y\right], G$, soil heat flux $[M J /$ $\left.\mathrm{m}^{2} / \mathrm{day}\right]$, T, daily air temperature $\left[{ }^{\circ} \mathrm{C}\right], u_{2}$, wind speed $[\mathrm{m} / \mathrm{s}]$, $e_{s}$, saturation vapor pressure $[k P a], e_{a}$, actual vapor pressure $[k P a], \Delta$, slope vapor pressure curve $\left[k P a /{ }^{\circ} \mathrm{C}\right], \gamma$, psychrometric constant $\left[\mathrm{kPa} /{ }^{\circ} \mathrm{C}\right]$.

The possibility of assessing $K_{c}$ from satellite data is represented in the relation between $K_{c}$ and NDVI (El-Shirbeny et al., 2019). Equation (5) shows the relation between $K_{c}$ and NDVI.

$$
K c=\frac{1.2}{N D V I_{d v}}\left(N D V I-N D V I_{m v}\right)
$$

where; 1.2 is the maximum $K_{c}, N D V I_{d v}$ is the difference between the minimum and maximum NDVI value for vegetation, and NDVI ${ }_{m v}$ is the minimum NDVI value for vegetation.

The NDVI categorizes the land surface classes according to red $(R)$ and near-infrared (NIR). The $R$ is represented as band 4 in Landsat-8, while NIR is represented as band 5 in Landsat-8. The $R$ and NIR are used to calculate NDVI as follows:

$$
N D V I=\frac{N I R-R}{N I R+R}
$$

The calculated Kc from radar satellite data differs from the derived Kc from optical satellite data. The backscattered VVpolarization data $(\mathrm{dB})$ show $\mathrm{Kc}$; values greater than 0.18 are considered bare soil and urban, with no vegetation or moist soil. While the numbers ranging from 0.18 to 0.03 reflect various phases of crop development with varying amounts of water content. Surface water with a high potential for evaporation is defined as data ranging from 0.03 to zero. The utilized relation between backscattered VV-polarization data and $\mathrm{Kc}$ is shown in Figure (4).

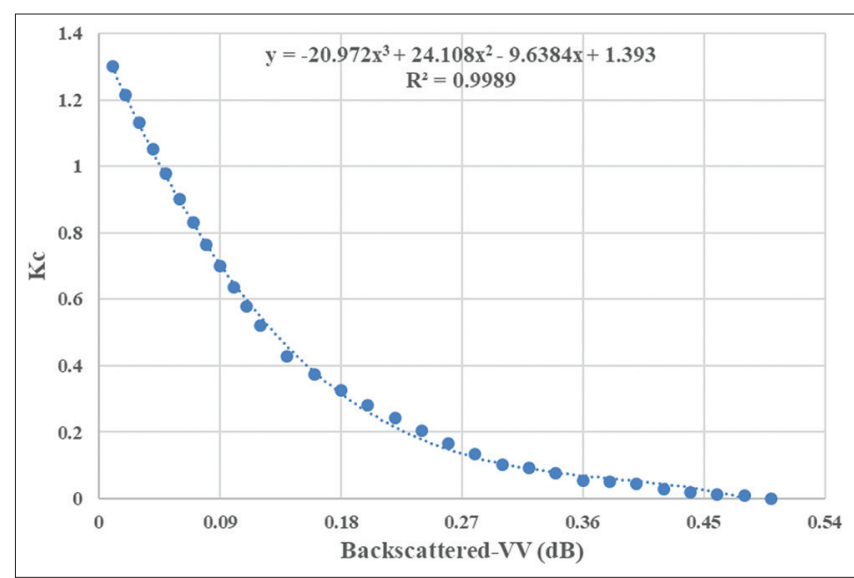

Figure 4: the relation between the backscattered $V V$-polarization data and $K_{c}$

The relation between the Crop Water Stress Index (CWSI) and actual evapotranspiration $\left(E T_{a}\right)$ has a unique mathematical relationship as follows:

$$
\mathrm{ETa}=(1-\mathrm{CWSI}) * \mathrm{ETc}
$$

The proposed CWSI process was established and developed as an empirical method (Jackson et al., 1981; Jackson, 1982). The theoretical part is established based on the difference between radiative temperature from well-watered crops and water-stressed crops as follows:

$$
\mathrm{CWSI}=\frac{\Delta \mathrm{T}-\Delta \mathrm{Tm}}{\Delta \mathrm{Tx}-\Delta \mathrm{Tm}}
$$

Where: $\Delta T$ is the difference between surface and air temperature. The $\Delta T m$, is the difference between minimum surface and air temperature and $\Delta T x$, is the difference between maximum surface and air temperature.

The subordinate border of $\Delta T$ happens through non-waterstressed circumstances. On the contrary, the superior border of $\Delta T$ happens through fully-water-stress environments. The CWSI fluctuates from zero to one, where zero shows no stress while one shows maximum stress (Jackson et al., 1981).

\section{Root Mean Square Error (RMSE)}

The RMSE was applied to assess the reliability of Landsat-8, Sentinel-1, and combination methods for application.

$$
R M S E=\sqrt{\sum_{i=1}^{n} \frac{\left(\mathrm{X}_{i}-\mathrm{X}_{\mathrm{obs}}\right)^{2}}{n}}
$$

Where; $n$ is a number of observations, Xobs is the observed value for sample $i$, and $X i$ is the resulted value for sample $i$.

\section{RESULTS AND DISCUSSIONS}

\section{Land Use Map}

Creating land use maps using remote sensing data and GIS methods plays a dynamic role in controlling and planning 
human-environmental interactions, such as agricultural growth, resource consumption, distribution, and urbanization (Hegazy \& Kaloop, 2015; Yang et al., 2017). The land use map is created to understand the variance in ET maps and, as a result, the quality of ET map descriptions based on satellite data.

Landsat-8 data has been categorized into three groups in order to create land use maps for the research region. The urban class (pink) is distributed across the research region and represents domestic dwelling areas (cities and villages), including major highways. The agricultural area class (green) indicates cultivated lands (field crops, vegetable crops, and horticultural crops). The water canals class (blue) is a longitudinal feature that traverses the research region from east to west, providing fresh water for irrigation purposes (Figure 5).

\section{Evapotranspiration Seasonal Maps}

ET is influenced by meteorological factors like radiation, air temperature, humidity, and wind speed. The ET rate is determined by crop type, transpiration resistance, crop height, crop roughness, reflectiveness, soil cover, and crop rooting properties. Aside from soil salinity, inadequate soil fertility, restricted fertilizer usage, complex or impenetrable soil horizons, disease and insect control failure, and poor soil management may all limit agricultural yield and decrease ET (Allen et al., 1998).

The ETo is computed using the FPM model, which was fed weather data from the zagazig meteorological station. The ETo was used with two types of Kc: the first is based on Landsat-8 data, while the second is based on Sentinel-1 data. To compute ETa, the CWSI is used with ETo and the extracted Kc from Landsat-8. The ETa maps are created using Landsat-8 (Figure 6) and Sentinel-1 data (Figure 7).

The urban has a low ETa value (near zero) according to the Landsat-8 ETa map, indicating that it is well-classified compared to the land use map (Figure 5). A low value in urban has a low value in NDVI analysis, resulting in a low Kc calculation and a

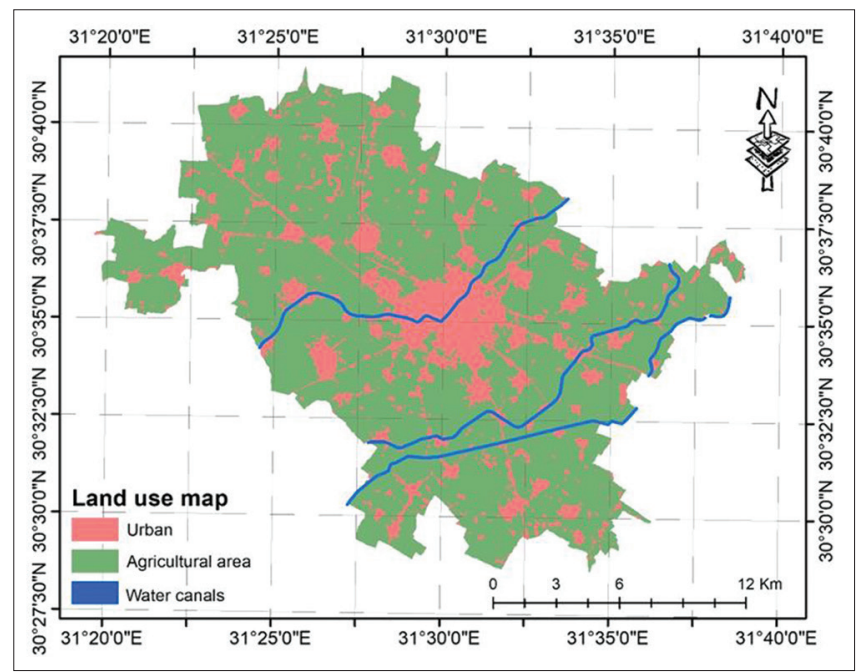

Figure 5: land used map includes three classes; urban, agricultural, and water canals low water content (dry target), resulting in a low CWSI score. The cultivated areas are clearly defined when water consumption is high, although they vary from place to location depending on crop type, crop stage, vegetation density, and water availability. In this technique, water canals are not differentiated; canals recorded low water use and appeared roads. It occurred because shallow NDVI values (negative values near to zero) measured in the water were reflected in the Kc calculation. The ETa reached $836.7 \mathrm{~mm} / \mathrm{season}$.

According to the Sentinel-1 ETa map, the ETa reached 954.8 ( $\mathrm{mm} /$ season). This technique clearly distinguishes water canals; canals recorded extremely high water usage and showed as a distinct class (dark red) compared to the land use map (Figure 5). The water recorded shallow dB values (near to zero), which was reflected in the dual Kc computation as vice versa. The farmed areas are well-defined, and water consumption is substantial but varies depending on crop type, crop stage, vegetation density, and water availability. The urban has a low

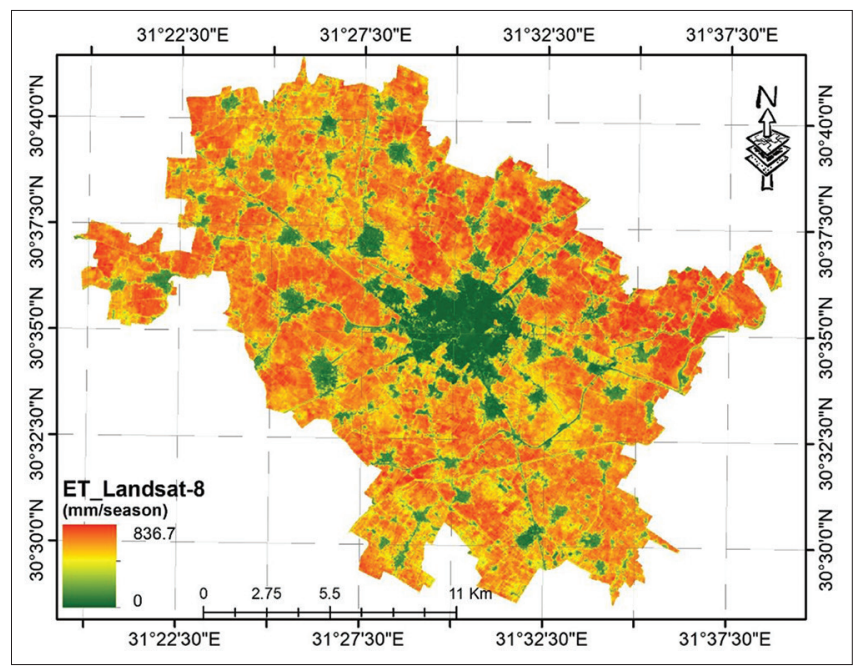

Figure 6: Evapotranspiration seasonal map produced based on Landsat-8 satellite data

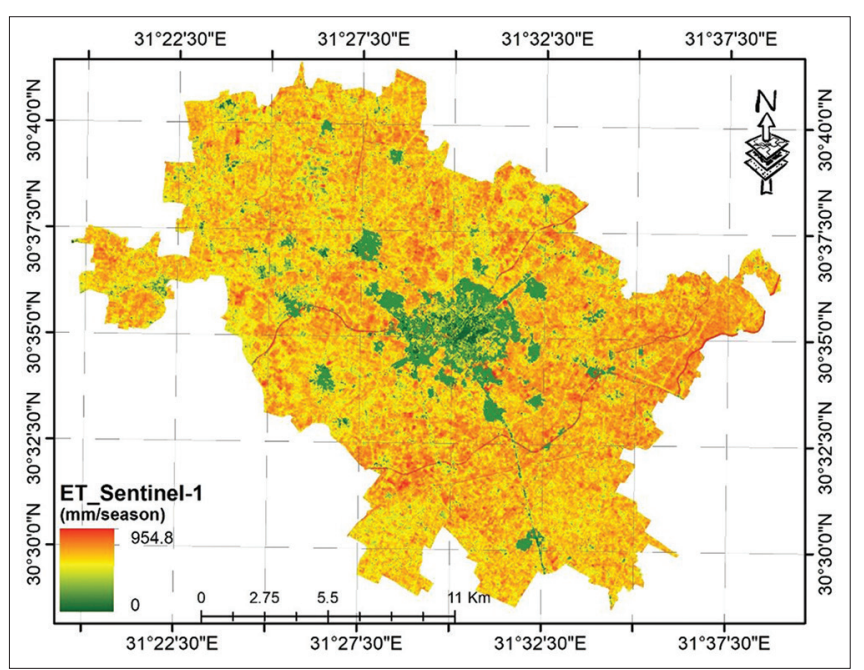

Figure 7: Evapotranspiration seasonal map produced based on Sentinel-1 radar data. 
ETa value (near to zero), even though it is poorly categorized compared to the land use map (Figure 5). A low number in urban has a high value in $\mathrm{dB}$ analysis, indicating a reverse relationship in dual Kc calculation and low water content (dry target). Interference exists between certain cultivated regions and some homogenous low elevation urban areas, which reflect near backscattering values.

\section{$E T_{a}$ Data Analysis}

The study of ETa $(\mathrm{mm} /$ day) shows an imminent relationship between Lysimeter and the combination of sentinel-l and Landsat-8, with median values of 4.3 ( $\mathrm{mm} /$ day) and 4.2 (mm/day) and mean values of 5 (mm/day) and $4.4(\mathrm{~mm} /$ day $)$ correspondingly. For the Lysimeter, Sentinel-1, Landsat-8, and combination techniques, the first quartile $(\mathrm{Q} 1)$ recorded 3.9, 5.1, 2.9, and 3.8 ( $\mathrm{mm} /$ day), respectively. For Lysimeter, Sentinel-1, Landsat- 8 , and the combination technique, the third quartile (Q3) recorded 5.9, 6.3, 4.3, and 5.1 (mm/day), respectively. On May 31, 2016, Lysimeter detected outliers; ETa showed 10.7 $(\mathrm{mm} /$ day). In summary, the ETa study revealed a 14 percent overestimation in the Sentinel-1 approach, whereas the Landsat-8 and combination methods revealed a 23 percent and 11 percent underestimate, respectively. Figure 8 depicts a boxplot analysis for ETa (mm/day) calculated from Lysimeter readings, Sentinel-1, Landsat-8, and a combination of Sentinel-1 and Landsat-8.

\section{Validation of $E T_{a}$}

Sekertekin et al. (2018) used RMSE and coefficient of determination $\left(\mathrm{R}^{2}\right)$ to assess Sentinel-l SAR data, resulting in excellent findings; the results were close to in-situ measurements, with RMSE and $\mathrm{R}^{2}$ as high as 2.46 percent and 0.84 , respectively.

The RMSE showed that all techniques produced acceptable results. The RMSE for Sentinel-1, Landsat-8, and combination techniques was $0.89,0.24$, and 0.31 (mm/day), respectively. The best technique is Landsat-8, although Sentinel-1 may be utilized on overcast days. In the winter, the impacts of overcast

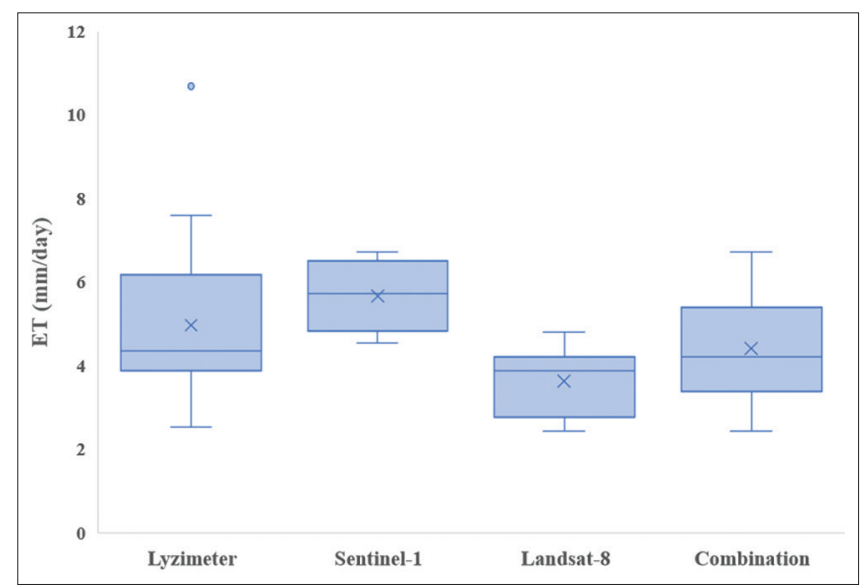

Figure 8: Boxplot analysis for $E T_{a}(\mathrm{~mm} /$ day) produced based on Lysimeter measurements, Sentinel-1, Landsat-8, and the combination between Sentinel-1 and Landsat-8 days on Landsat-8 data availability are obvious. As a result, radar data is preferred above optical data during foggy seasons. For agricultural water accounting, a combination of optical and radar sensors will provide superior results.

The relationship between generated ETa measured by Lysimeter and produced ETa measured by Sentinel-1 data was linear, with an $\mathrm{R}^{2}$ as high as 0.77 (Figure 9). This relationship shows that Sentinel-1 data offer adequate results for evaluating ETa. The sensitivity of Sentinel-l data to soil moisture content aids in obtaining excellent ETa findings. These findings have been confirmed by (El-Shirbeny \& Abu-Taleb, 2017; Sekertekin et al., 2018).

While the linear relationship between generated ETa based on Lysimeter readings and produced ETa based on Landsat-8 data was strong, with an $\mathrm{R}^{2}$ as high as 0.63 (Figure 10), this relationship shows that the Landsat- 8 data provide adequate results for estimating ETa. The sensitivity of thermal data to plant and soil water content contributes to excellent ETa results. These results are determined by (Jackson et al., 1981; El-Shirbeny et al., 2014a).

While the relationship between generated ETa based on Lysimeter readings and produced ETa based on Sentinel-1 and Landsat-8 data was exponential, with $\mathrm{R}^{2}$ as high as 0.8 (Figure 11 ). This relationship demonstrates that the combination approach produces the best results for estimating ETa. The sensitivity of

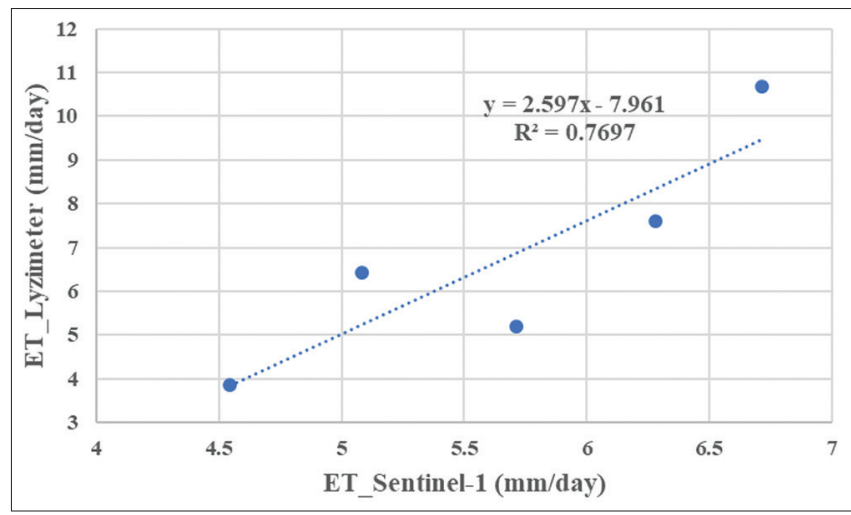

Figure 9: The relation between $E T_{a}(\mathrm{~mm} /$ day) produced based on Lysimeter measurements and Sentinel-1 data

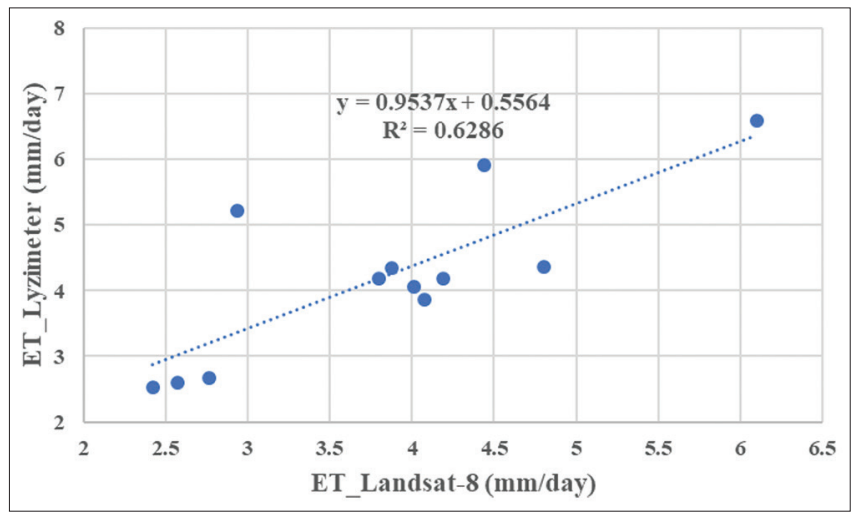

Figure 10: The relation between $E T_{a}(\mathrm{~mm} /$ day) produced based on Lysimeter measurements and Landsat- 8 data 


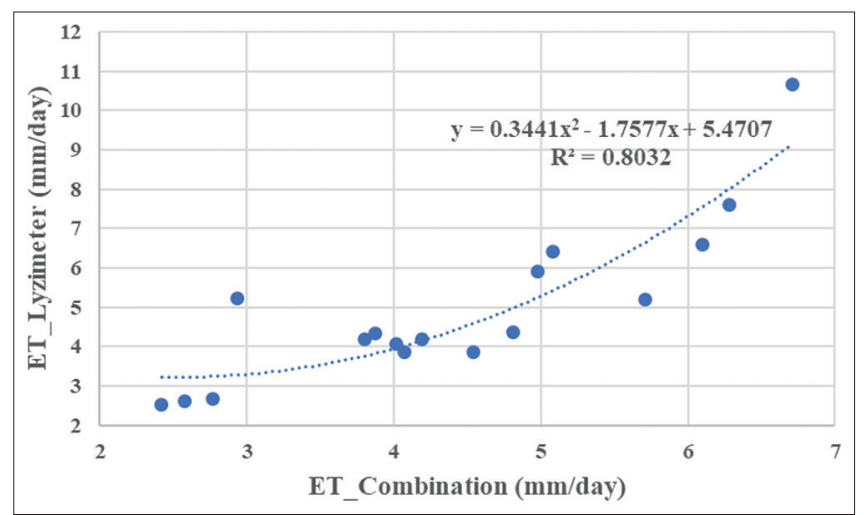

Figure 11: The relation between $E T_{a}(\mathrm{~mm} /$ day) was produced based on Lysimeter measurements and the combination of Sentinel-1 and Landsat-8 data

Table 2: used satellite data time distribution for Landsat-8 and Sentinel-1.

\begin{tabular}{lcllll}
\hline No & Sensed date & Satellite & No & Sensed date & Satellite \\
\hline 1 & 30 May 2016 & Landsat-8 & 10 & 18 Jul 2016 & Sentinel-1 \\
2 & 31 May 2016 & Sentinel-1 & 11 & 26 Jul 2016 & Landsat-8 \\
3 & 08 Jun 2016 & Landsat-8 & 12 & 30 Jul 2016 & Sentinel-1 \\
4 & 12 Jun 2016 & Sentinel-1 & 13 & 02 Aug 2016 & Landsat-8 \\
5 & 15 Jun 2016 & Landsat-8 & 14 & 11 Aug 2016 & Landsat-8 \\
6 & 24 Jun 2016 & Landsat-8 & 15 & 18 Aug 2016 & Landsat-8 \\
7 & 01 Jul 2016 & Landsat-8 & 16 & 23 Aug 2016 & Sentinel-1 \\
8 & 01 Jul 2016 & Landsat-8 & 17 & 27 Aug 2016 & Landsat-8 \\
9 & 17 Jul 2016 & Landsat-8 & & & \\
\hline
\end{tabular}

radar and thermal data to soil and plant water content aids in delivering approved ETa products.

\section{CONCLUSION}

Weather conditions are significant driving elements in agriculture, but water availability is an essential driving factor in crop life cycle completion, with water scarcity directly impacting crop output in terms of yield quantity and quality. Water scarcity may occur throughout the whole agricultural season or at discrete times. Optical remote sensing is very helpful. However, it is rendered worthless during overcast days. The SAR C-band signals penetrate through the cloud and collect data through backscattering. Backscattering (dB) is a helpful method for determining the combined water content of crop and soil, mainly when there is cloud cover. The ETa may be calculated using both active and optical data. The findings were positive, with the RMSE for Sentinel-1, Landsat-8, and combination techniques being $0.89,0.24$, and 0.31 ( $\mathrm{mm} /$ day), respectively. The Landsat- 8 satellite is the best for calculating ETa, although Sentinel-1 may be used on overcast days. As a result, radar data is suggested for overcast conditions when optical data is unavailable. To achieve large-scale monitoring, a combination of optical and radar sensors is suggested for agricultural water accounting.

\section{Data Availability}

The authors affirm that the evidence confirming this study's conclusions is included in the paper and its supplementary materials. For more available satellite data, the websites of NASA and ESA support free data downloading for weather and land monitoring satellites; Landsat-8 (https://earthexplorer. usgs.gov/) and Sentinel-1 (https://scihub.copernicus.eu/dhus/\#/ home). The weather and satellite data are collected through Central Laboratory for Agricultural Climate (CLAC) and National Authority for Remote Sensing and Space Sciences (NARSS).

\section{ACKNOWLEDGMENT}

NASA and ESA satellite data access were critical in this work, and this work emerged as a result of their data availability. This work is considered as cooperation among the National Authority for Remote Sensing and Space Sciences (NARSS), Arab Organization for Agricultural Development (AOAD), International Center for Agriculture Research in Dry Areas (ICARDA), and the Central Laboratory for Agricultural Climate (CLAC).

\section{REFERENCES}

Aboelghar, M., Arafat, S., Saleh, A., Naeem, S., El-Shirbeny, M., \& Belal, A. (2010). Retrieving leaf area index from SPOT4 satellite data. The Egyptian Journal of Remote Sensing and Space Science, 13(2), 121127. https://doi.org/10.1016/j.ejrs.2010.06.001

Allen R G., Tasumi, M., \& Trezza, R (2007). Satellite-based energy balance for mapping evapotranspiration with internalized calibration (METRIC) - model J. Journal of Irrigation and Drainage Engineering, 133(4), 380-393. https://doi.org/10.1061/(ASCE)07339437(2007)133:4(380)

Allen, R.G., Pereira, L. S., Raes, D., \& Smith, M. (1998). Crop evapotranspiration: Guidelines for computing crop water requirements. United Nations Food and Agriculture Organization, Irrigation and Drain. Paper No. 56, Rome, Italy.

ASCE-EWRI (2005). The ASCE Standardized Reference Evapotranspiration Equation. Technical Committee report to the Environmental and Water Resources Institute of the American Society of Civil Engineers from the Task Committee on Standardization of Ref. Evapotranspiration. $173 \mathrm{p}$

Baioumy, E. M., El-Shirbeny, M. A., El-Ansary, M. Y., \& Awad, M. A (2016). Estimation of Regional Evapotranspiration Based on Tri-Angle Method Using Thermal and VNIR Data.

Bastiaanssen, W. G. M., Menenti, M., Feddes, R. A., \& Holtslag, A. A. $M$ (1998). A remote sensing surface energy balance algorithm for land (SEBAL) 1. Formulation. Journal of Hydrology, 212-213, 198-212. https://doi.org/10.1016/S0022-1694(98)00253-4

Bastiaanssen, W. G. M., Cheema, M. J. M., Immerzeel, W. W., Miltenburg, I. J., \& Pelgrum, H. (2012). Surface energy balance and actual evapotranspiration of the transboundary Indus Basin estimated from satellite measurements and the ETLook model. Water Resources Research, 48(11), W11512. https://doi.org/10.1029/2011WR010482

Dibella, C. M., Rebella, C. M., \& paruelo, J. M (2000). Evapotranspiration estimates using NOAA AVHRR imagery in the pama region of Argantina, International Journal of Remote Sensing, 21(4), 791-797. https://doi.org/10.1080/014311600210579

El-Shirbeny, M. A., \& Abdellatif, B. (2017). Reference Evapotranspiration Borders Maps of Egypt Based on Kriging Spatial Statistics Method. International Journal of Geomate, 13, 1-8. https://doi. org/10.21660/2017.37.63048

El-Shirbeny, M. A., \& Abutaleb, K. A. (2018). Monitoring of water-level fluctuation of Lake Nasser using altimetry satellite data. Earth Systems and Environment, 2(2), 367-375.

El-Shirbeny, M. A., Abdellatif, B., Ali, A. M., \& Saleh, N. H. (2016). Evaluation of Hargreaves based on remote sensing method to estimate potential crop evapotranspiration. International Journal of Geomate, 11(23), 2143-2149. https://doi.org/10.21660/2016.23.1122

El-Shirbeny, M. A., Aboelghar, M. A., Arafat, S. M., \& El-Gindy, A. G. M. 
(2014a). Assessment of the Mutual Impact between Climate and Vegetation Cover Using NOAA-AVHRR and Landsat Data in Egypt. Arabian Journal of Geosciences, 7, 1287-1296. https://doi. org/10.1007/s12517-012-0791-3

El-Shirbeny, M. A., Ali, A. M., Khdery, G. A., Saleh, N. H., Afify, N. M., Badr, M. A., \& Bauomy, E. M. (2021). Monitoring agricultural water in the desert environment of New Valley Governorate for sustainable agricultural development: a case study of Kharga. Euro-Mediterranean Journal for Environmental Integration, 6(2), 1-15.

El-Shirbeny, M. A., Ali, A. M., Savin, I., Poddubskiy, A., \& Dokukin, P. (2021). Agricultural water monitoring for water management under pivot irrigation system using spatial techniques. Earth Systems and Environment, 5(2), 341-351. https://doi.org/10.1007/s41748-02000164-8

El-Shirbeny, M. A., Ali, A., \& Saleh, N. (2014b). Crop water requirements in Egypt using remote sensing techniques. Journal of Agricultural Chemistry and Environment, 3, 57-65. https://doi.10.4236/ jacen.2014.32B010

El-Shirbeny, M. A., Alsersy, M. A. M., Saleh, N. H., \& Abu-Taleb, K. A (2015). Changes in irrigation water consumption in the Nile Delta of Egypt assessed by remote sensing. Arabian Journal of Geosciences, 8(12), 10509-10519. https://doi.org/10.1007/s12517-015-2005-2

El-Shirbeny, M. A., Mohamed, E. S., \& Negm, A. (2019). Estimation of Crops Water Consumptions Using Remote Sensing with Case Studies from Egypt. In Conventional Water Resources and Agriculture in Egypt (pp. 451-469). Springer, Cham.

El-Shirbeny, M., \& Abutaleb, K. (2017). Sentenel-1 radar data assessment to estimate crops water stress. World Journal of Engineering and Technology, 05(02), 47-56. https://doi.org/10.4236/wjet.2017.52B006

Ghandour, A., Snyder, R. L., Frame, K., Eching, S., Temesgen, B., \& Davidoff, B (2007). Converting KC Values between ETo and ETr. 1-6. https:// doi.org/10.1061/40856(200)258

Hegazy, I. R., \& Kaloop, M. R (2015). Monitoring urban growth and land use change detection with GIS and remote sensing techniques in Daqahlia Governorate Egypt. International Journal of Sustainable Built Environment, 4(1), 117-124. https://doi.org/10.1029/ WR017i004p01133

Idso, S. B., Jackson, R. D., Pinter, P. J., Reginato, R. J., \& Hatfield, J. L. (1981). Normalizing the stress degree day for environmental variability. Agricultural Meteorology, 24, 45-55. https://doi.org/10.1016/00021571(81)90032-7

Jackson, R. D. (1982). Canopy temperature and crop water stress index. Advances in Irrigation Journal, 1, 43-85. https://doi.org/10.1016/ B978-0-12-024301-3.50009-5

Jackson, R. D., Idso, S. B., Reginato, R. J., \& Pinter, P. J. (1981). Canopy temperature as a crop water stress indicator. Water Resources
Research, 17, 1133-1138. https://doi.org/10.1029/WR017i004p01133 Li, M., Zang, S., Zhang, B., Li, S., \& Wu, C. (2014). A review of remote sensing image classification techniques: The role of spatio-contextual information. European Journal of Remote Sensing, 47(1), 389-411. https://doi.org/10.5721/EuJRS20144723

Mohamed, E. S., Ali, A., El-Shirbeny, M., Abutaleb, K., \& Shaddad, S. M. (2020). Mapping soil moisture and their correlation with crop pattern using remotely sensed data in arid region. The Egyptian Journal of Remote Sensing and Space Science, 23(3), 347-353.

Oki, T., \& Kanae, S. (2006). Global hydrological cycles and world water resources. Science, 313, 1068-1072. https://doi.org/10.1126/ science. 1128845

Rwasoka, D. T., Gumindoga, W., \& Gwenzi, J. (2011). Estimation of Actual Evapotranspiration Using the Surface Energy Balance System (SEBS) Algorithm in the Upper Manyame Catchment in Zimbabwe. Physics and Chemistry of the Earth, 36, 736-746. https://doi.org/10.1016/j. pce.2011.07.035

Saxton, K. E., \& Willey, P. H. (2006). The SPAW model for agricultural field and pond hydrologic simulation. P. 401-435. In V. P. Singh \& D. K. Frevert (Eds.), Watershed models. CRC Press, Boca Raton, FI.

Şekertekin, A., Marangoz, A. M., \& Abdikan, S. (2018). Soil moisture mapping using Sentinel-1A synthetic aperture radar data. International Journal of Environment and Geoinformatics, 5(2), 178-188. https:// doi.org/10.30897/ijegeo.425606

Stokcle, C. O., \& Dugas, W. A. (1992). Evaluating Canopy TemperatureBased Indices for Irrigation Scheduling. Irrigation Science, 13, 31-37. https://doi.org/10.1007/BF00190242

Su, Z. (2002). The Surface Energy Balance System (SEBS) for estimation of turbulent heat fluxes. Hydrology and Earth System Sciences, 6(1), 85-99.

Tadesse, T., Senay, G. B., Berhan, G., Regassa, T., \& Beyen, S. (2015) Evaluating a Satellite-Based Seasonal Evapotranspiration Product and Identifying Its Relationship with other Satellite-Derived Products and Crop Yield: A Case Study for Ethiopia. International Journal of Applied Earth Observation and Geoinformation, 40, 39-54. https:// doi.org/10.1016/j.jag.2015.03.006

Tolba, R. A., El-Shirbeny, M. A., Abou-Shleel, S. M., \& El-Mohandes, M. A. (2020). Rice acreage delineation in the Nile Delta based on thermal signature. Earth Systems and Environment, 4(1), 287-296.

Wu, B. F., Xiong, J., \& Yan, N. N. (2008). ETWatch for monitor regional evapotranspiration with remote sensing. Advances in Water Science, 19(5), 671-678.

Yang, D., Fu, C., Smith, A. C., \& Yu Q. (2017). Open land-use map: a regional land-use mapping strategy for incorporating OpenStreetMap with earth observations. Geo-spatial Information Science, 20(3), 269-281. https://doi.org/10.1080/10095020.2017.1371385 